\title{
Implementasi Rambu Rambu Keselamatan dan Kesehatan Kerja (K3) Sebagai Sarana Pemenuhan HAM Narapidana di Lembaga Pemasyarakatan
}

\author{
Lutfi Kurniawan \\ Politeknik IImu Pemasyarakatan \\ lutfi1998@gmail.com
}

DOI: $10.23917 /$ laj.v5i1.10419

Submission
Track:
Received:
01 Maret 2020
Final Revision:
21 Maret 2020
Available online:
28 April 2020
Corresponding
Author:
Lutfi Kurniawan
lutfi1998@gmail.com

\begin{abstract}
ABSTRAK
Jumlah penghuni Lembaga Pemasyarakatan (Lapas) pada saat ini yang melebihi kapasitas dan letak geografis Indonesia yang berada pada lempeng mediterania sangat rawan terjadinya bencana. Namun hingga saat ini belum ada rambu rambu keselamatan dan kesehatan kerja (K3) berupa jalur evakuasi dan titik kumpul di dalam lapas. Kasus baru baru ini yang terjadi di Indonesia yaitu runtuhnya tembok Lapas kelas IIA palu karena gempa berkekuatan 7,4 SR .Dari kejadian tersebut tercatat sebanyak 1.425 narapidana dan tahanan kabur dengan alasan menyelamatkan diri. Penelitian ini bertujuan membahas mengenai bagaimana evakuasi narapidana ketika terjadi bencana baik bencana alam maupun bencana lainya dengan tetap mengutamakan keamanan dan ketertiban di dalam Lapas. Penelitian ini menggunakan pendekatan kualitatif dengan melakukan observasi langsung sebagai data primer dan data sekunder berupa kajian teori dan berita media massa. Hasil dari penelitian ini yaitu terumusnya tata cara pelaksanaan rambu rambu $K 3$ dalam rangka pemenuhan HAM narapidana. Penelitian ini membahas mengenai pentingnya rambu rambu K3 untuk mengantisipasi, meminimalisir korban jiwa, memberikan rasa aman dan keselamatan pribadi bagi narapidana. Kebaruan Penelitian ini adalah membahas mengenai pelaksanaan rambu rambu $K 3$ dalam rangka pemenuhan HAM narapidana yang selama ini kurang diketahui dan diperhatikan oleh masyarakat luas. Selama ini pandangan masyarakat terhadap narapidana masih negatif, narapidana dianggap sebagai sampah masyarakat dan harus mendapat pembalasan dengan dimasukan ke dalam lapas. Dengan penelitian ini diharapkan dapat mengubah pola pikir masyarakat terhadap narapidana.
\end{abstract}

Kata Kunci: HAM, Rambu rambu K3, Lembaga Pemasyarakatan 


\begin{abstract}
The number of inmates of the Penitentiary at this time that exceeds the capacity and geographical location of Indonesia which is in the Mediterranean plate, is very prone to disasters. However, up to now, there are no Occupational Safety and Health Signs in the form of evacuation routes and gathering points in prisons. A recent case that occurred in Indonesia is the collapse of Class IIA prison walls hammers due to a magnitude 7.4 earthquake. Of these events there were 1,425 prisoners and prisoners fleeing on the grounds of escape. This study aims to discuss how evacuation of prisoners in the event of a disaster both natural disasters and other disasters by continuing to prioritize security and order in prison. This study uses a qualitative approach by direct observation as primary data and secondary data in the form of theoretical studies and mass media news. The results of this study are the formulation of the procedures for the implementation of Occupational Safety and Health Signs in order to fulfill the human rights of prisoners. This study discusses the importance of Occupational Safety and Health Signs to anticipate, minimize casualties, provide security and personal safety for prisoners. The novelty of this research is to discuss the implementation of Occupational Safety and Health Signs in the context of fulfilling the human rights of prisoners, which so far have not been known and considered by the wider community. During this time the public view of prisoners is still negative, prisoners are considered as community trash and must get retaliation by being put in prison. With this research it is hoped that it can change the mindset of the community towards inmates.
\end{abstract}

Keywords: HAM, Occupational Safety And Health (K3) signs, Penitentiary

\title{
PENDAHULUAN
}

HAM (Hak Asasi Manusia) adalah suatu hak yang melekat pada diri manusia sejak lahir sebagai suatu anugerah dari Tuhan yang maha esa (Pangaribuan, 2017). HAM bersifat alamiah dan pokok tidak bisa dicabut,dihilangkan dan dimusnahkan oleh siapapun. Begitupun dengan narapidana, walaupun status mereka dirampas haknya oleh negara, dalam arti lain orang yang menyandang status sebagai pelanggar hukum, namun bukan berarti HAM mereka juga dirampas.

HAM wajib diberikan, tidak boleh dihalang halangi oleh apapun dan siapapun (Hamidah, 2008). HAM bersifat universal yang berarti berlaku dimana saja dan untuk siapa saja tidak memandang status mereka (Triwahyuningsih, 2018). Sesuai dengan pasal 5 poin $\mathrm{f}$ 
Undang undang No. 12 tahun 1995 tentang Pemasyarakatan bahwa kehilangan kemerdekaan merupakan satu satunya penderitaan (Indonesia, 1995). Maka dari itu tidak berhak negara atau pihak manapun untuk menambah kesakitan yang dialami oleh para pelanggar hukum. Hilang kemerdekaan bergerak karena harus menjalani pembinaan di dalam Lapas merupakan satu satunya kesakitan yang dialami oleh narapidana. Maka dari itu narapidana juga harus tetap mendapatkan jaminan perlindungan HAM sesuai dengan peraturan perundang undangan yang berlaku di Indonesia.

Di dalam Undang Undang Dasar Negara Republik Indonesia Tahun 1945 (UUD 1945) telah diatur mengenai Hak Asasi Manusia di dalam pasal 28 A-J. Negara disini yaitu Lembaga Pemasyarakatan dan Rumah Tahanan Negara sebagai unit pelaksana teknis di pemasyarakatan harus memberikan pemenuhan HAM terhadap para terpidana. Hakekat dari HAM itu sendiri adalah suatu usaha untuk menjaga keselamatan eksistensi pada diri manusia itu sendiri secara utuh melalui aksi keseimbangan antara kepentingan individu dengan kepentingan banyak orang.

Manusia memilik hak yang khas berbeda dengan hewan, manusia memiliki akal pikiran dan bukan hanya sekedar tumbuh namun juga berpikir (Jasman, 1997). Upaya untuk menghormati, melindungi dan menjunjung tinggi HAM menjadi tanggung jawab bersama antara individu, pemerintah (aparatur pemerintah baik sipil maupun militer) dan negara (Triwahyuningsih, 2018). Kewajiban dan tanggung jawab Pemerintah dalam pasal 71 s.d. 72 Undang Undang No 39 Tahun 1999 ttg Hak Asasi Manusia : Pasal 71 Pemerintah wajib dan bertanggung jawab menghormati, melindungi, menegakan, dan memajukan HAM. Pasal 72, langkah implementasi yang efektif dalam bidang epoleksosbudhankam dan bidang lain. Maka dari itu perlunya peran serta negara terhadap upaya pemenuhan HAM narapidana.

Letak geografis indonesia berada di antara 3 lempeng benua yaitu berada di sebelah selatan yaitu Lempeng Indo-Australia yang bergerak ke utara, disebelah timur oleh Lempeng Pasifik yang bergerak ke arah barat, dan di sebelah utara oleh Lempeng Eurasia yang bergerak ke arah tenggara (Kartono Tjandra, 2017). Indonesia juga berada di area Ring of fire dengan dikelilingi oleh puluhan gunung berapi yang masih berstatus aktif (Wiwaha, Mei, \& Rachmawati, 2016). Ditambah lagi dengan kondisi penghuni Lapas dan Rutan Indonesia yang overkapasitas, sangat rawan terjadinya kecelakaan seperti kerusuhan ,kebakaran dan sebagainya. Bahkan tidak menutup kemungkinan akibat adanya gempa bumi dapat 
menyebabkan kerusuhan dan pengrusakan fasilitas oleh para narapidana karena dalam keadaan panik dan tertekan untuk menyelamatkan diri. Sehubungan dengan kejadian tersebut, maka dari itu perlunya pemenuhan HAM sesuai dengan pasal 28 A dan G UUD 1945. Pasal 28 A UUD 1945 yaitu bahwa setiap orang berhak untuk hidup serta berhak mempertahankan hidup dan kehidupannya.

John Locke mengungkapkan bahwa ada tiga hak yang tidak bisa dihilangkan dari diri manusia yaitu hak untuk hidup, hak kebebasan dan hak atas tanah milik. Menurut HAM dengan mengangkat nilai yang bertujuan dengan syairat Islam yaitu Hifzh an-Nafs yang berarti perlindungan jiwa meliputi hak untuk hidup, hidup layak, hak merdeka (Estetika, 2016). Di sini para narapidana yang sedang menjalankan masa pidana nya didalam tembok wajib mendapatkan haknya untuk tetap hidup dan mempertahankan hidupnya walaupun telah dirampas hak kemerdekaan bergeraknya oleh negara.

HAM wajib dipenuhi, ditegakkan dan dilindungi oleh segenap bangsa dan negara (Matompo, 2014). Negara harus hadir dan memfasilitasi dalam rangka pemenuhan HAM bagi para narapidana.Kemudian pasal 28 G ayat 1 UUD 1945 tertera bahwa setiap orang di sini narapidana berhak atas perlindungan diri pribadi serta berhak mendapatkan rasa aman dari ancaman. Menurut John Locke, ia membahas mengenai hak individu bawasannya hak untuk hidup dan mempertahankan kehidupannya merupakan suatu hal yang sangat penting dari manusia

Kasus kecelakaan akibat bencana alam maupun kerusuhan masih kerap terjadi di lapas dan rutan Indonesia. Hal tersebut bisa menjadi gambaran mengenai belum terpenuhinya HAM narapidana terkait hak untuk hidup dan perlindungan pribadi. Dikutip dari media massa online yaitu CNN Indonesia tercatat sebanyak 1.425 narapidana dan tahanan kabur dari Lapas Kelas IIA Palu (CNN Indonesia, 2018). Dari berita tersebut dijelaskan keterangan dari Direktur Jendral Pemasyarakatan Sri Puguh Budi Utami bahwa para narpidana dan tahanan sudah berkumpul dilapangan ketika terjadi bencana gempa, namun kondisi berubah panik ketika terjadi gempa susulan dan tanah di lapangan mulai retak dengan mengeluarkan air. Seketika narapidana langsung panik dan berusaha menyelamatkan diri dengan berlari menuju dua blok yang sudah bobol temboknya. Kemudian narapidana lari keluar lapas untuk menyelamatkan diri. Kasus lainya baru baru ini yang terjadi di Sumatera Utara yaitu kerusuhan yang terjadi di Rutan Kabanjahe. Kerusuhan disebabkan oleh penolakan oleh pihak narapidana ketika akan 
dilakukan razia oleh petugas dan berujung dengan pembakaran rutan yang dilakukan oleh narapidana.

Dikutip dari media massa online yaitu CNN Indonesia pihak TNI batalyon 125 Simbisa, Polres Tanah Karo dan petugas Rutan Kabanjahe melakukan upaya evakuasi narapidana dengan cara melalui tembok ke rumah dinas kepala rutan kabanjahe, kemudian para narapidana dibawa ke Polres Tanah Karo (CNN Indonesia, 2020). Diperlukan upaya melindungi narapidana saat bencana dengan tanpa mengesampingkan keamanan dan ketertiban.

Mencermati kasus tersebut, berdasarkan dasar hukum terkait pelaksanaan rambu rambu K3 yaitu, UU RI No. 1 tentang Keselamatan Kerja, dan Permenaker RI No. Per 05/MEN/1996 tentang Sistem Manajemen Keselamatan Kerja bahwa semua perusahaan wajib melaksanakan SMK3. Peraturan Kementrian Kesehatan No.48 tentang Standar Keselamatan dan Kesehatan Kerja Perkantoran pasal 3 ayat 1 bahwa setiap pimpinan kantor dan/atau pengelola gedung wajib menyelenggarakan K3 perkantoran. Berdasarkan peraturan tersebut dijelaskan bahwa Pimpinan Lapas dan Rutan yaitu Kalapas/Karutan atau Pengelola Gedung (Tata Usaha) wajib mengadakan media keselamatan narapidana ketika terjadi suatu bencana alam berupa gempa bumi atau bencana lainya

K3 merupakan suatu ilmu yang mempelajari mengenai cara penerapan untuk mengantisipasi/mencegah adanya penyakit atau korban jiwa akibat adanya suatu kecelakaan (Sucita \& Broto, 2011). K3 sangat berkaitan erat dan tidak bisa dipisahkan dengan kecelakaan (Susihono \& Rini, 2013). Maka dari itu K3 bertujuan untuk memberikan perlindungan terhadap para pekerja agar mencapai hasil yang maksimal (Widari, 2018).

Perlunya suatu rambu rambu K3 sebagai media untuk membantu evakuasi ketika terjadi bencana di dalam lapas. Rambu rambu K3 adalah alat bantu untuk menginformasikan adanya suatu bahaya dan memberikan suatu peringatan kepada para pekerja disini yaitu sebagai objek dari lapas adalah para narapidana. Di dalam dunia kesehatan, keselamatan pasien juga sudah menjadi prioritas dalam aspek pelayanan yang ada di dalam rumah sakit dan sudah menjadi tuntutan kebutuhan dalam pelayanan kesehatan (Hetty Ismainar, 2015). Sama halnya di lembaga pemasyarakatan, narapidana merupakan pasien dan suatu prioritas. 
Berangkat dari hal tersebut maka berikut merupakan teori penyebab terjadinya kecelakaan kerja menurut H.W Heinrich pada tahun 1920-an. Yang pertama yaitu teori domino atau "Lost of Cousation Model"(Riswan Dwi Djatmiko, 2016). Teori tersebut menjelasakan rentenan kejadian sebelum terjadinya suatu kecelakaan. Ada juga teori penyebab kecelakaan lainya meliputi Pure Chane Theory, Accident Prone Theory, Three Main Factory Theory, Two Main Factory Theory, dan Human Factory Theory (Irzal, 2016)

Berdasarkan teori di atas dapat menjadi titik terang penyebab kecelakaan. Dengan memahami penyebab asal mula kecelakaan sehingga dapat menentukan kondisi seharusnya (das sollen) terkait pelaksanaan K3 di dalam lapas. Maka dari itu dapat dirumuskan masalah yaitu, apakah yang menjadi faktor-faktor penyebab kecelakaan berupa bencana yang menyebabkan tidak terpenuhinya HAM narapidana? Bagaimana kondisi seharusnya (das sollen) mengenai impelementasi rambu rambu K3 dalam rangka pemenuhan HAM narapidana? Tujuan dari penelitian ini untuk menemukan faktor penyebab kecelakan di dalam lapas, menganalisis bagaimana implementasi rambu rambu K3 terhadap pemenuhan HAM. Dari tulisan ini juga dapat menghasilkan suatu prosedur/tata cara evakuasi ketika terjadi bencana dengan tetap mengutamakan kemanan dan ketertiban didalam lapas. Diharapkan pelaksanaan rambu rambu K3 dapat diterapkan diseluruh Lapas dan Rutan di Indonesia sebagai upaya pemenuhan HAM narapidana.

\section{METODE PENELITIAN}

Metode yang digunakan di dalam penelitian ini ialah metode deskriptif dengan pendekatan kualitatif dengan sumber data berupa kondisi real atau kondisi sebenarnya yang terjadi di dalam lapas. Teknik pengumpulan data dengan melakukan observasi langsung sebagai data primer dan memanfaatkan berita media massa, gambar dan kajian teori sebagai data sekunder. Observasi memiliki arti yaitu proses mengumpulkan data yang berasal langsung dari lapangan (JR Raco, 2010). Dengan melakukan observasi diharapkan peneliti mendapatkan informasi secara menyeluruh, dikarenakan peneliti dapat terjun langsung dan menjadi pasrtisipan didalam Lapas. Melakukan observasi langsung juga dapat merubah mindset awal peneliti mengenai kondisi yang dialami oleh para narapidana di dalam Lapas. Lokasi penelitian di Lembaga Pemasyarakatan Kelas IIA Purwokerto yang beralamat di Jalan Pasukan Pelajar Imam, Tanahgaring, Pamijen, Kec. Sokaraja, Kabupaten Banyumas, Provinsi Jawa Tengah. 


\section{HASIL DAN PEMBAHASAN}

\section{A. Kondisi Ideal Pelaksanaan K3 di Lapas.}

Pelaksanaan rambu rambu K3 sudah banyak dilaksanakan di beberapa instansi, rumah sakit dan proyek pekerjaan bangunan . Rambu rambu K3 merupakan upaya memberikan arah untuk mencegah terjadinya kecelakaan (Nurkholis \& Adriansyah, 2017). Rambu rambu K3 dibuat dan dilaksanakan dengan ketentuan 1) untuk penunjuk arah dan titik kumpul dibuat dengan warna yang cerah dan kontras dengan tembok lapas berguna agar mudah di lihat dan mencolok sehingga mudah dikenali ketika sedang berada dalam situasi/kondisi yang panik, 2) untuk warna dari jalur evakuasi dan titik kumpul yaitu warna hijau karena menandakan zona aman pertolongan. Maka dari itu kondisi yang seharusnya terjadi di lapas adalah terdapat pelaksanaan rambu rambu K3 sebagai berikut :

1. Denah jalur evakuasi

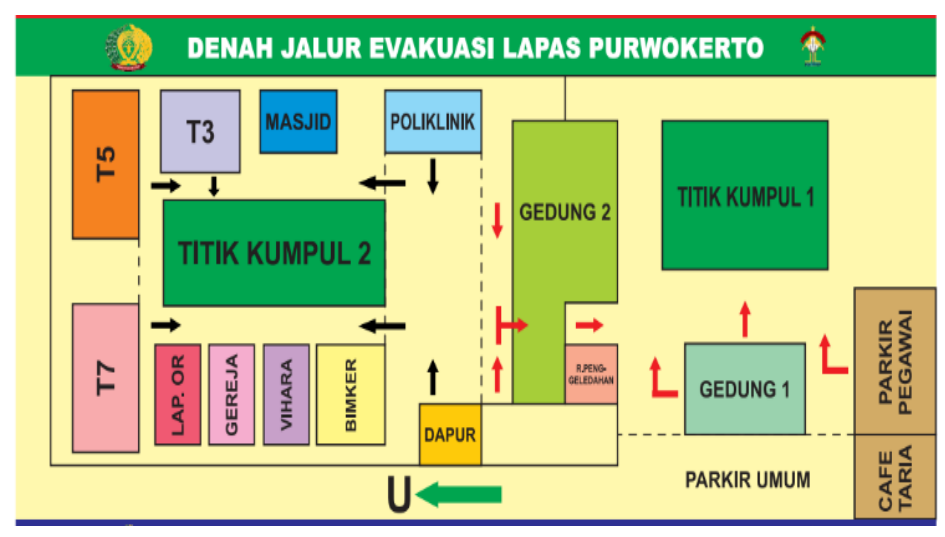

Gambar 1. Denah Jalur Evakuasi Lapas Purwokerto

Penjelasan :

a) Titik kumpul dibagi menjadi dua :

- Pertama yaitu titik kumpul 1 yaitu di pergunakan untuk titik kumpul bagi pengunjung dan pegawai yang sedang berada di lingkungan Lapas Purwokerto ketika terjadi bencana.

- Kedua adalah titik kumpul 2 yaitu dipergunakan untuk titik kumpul bagi Warga Binaan Pemasyarakatan (WBP) yang letaknya di area steril atau setelah pintu ke empat. Sengaja di bagi menjadi dua titik kumpul karena perlu kita ketahui demi tetap menjaga kemanan dan ketertiban maka untuk titik kumpul dipisah antara WBP dan masyarakat hal tersebut bertujuan agar tidak ada WBP yang kabur dari lapas. 
b) Warna petunjuk arah memiliki ketentuan sebagai berikut :

- Jalur warna merah diperuntukan untuk pegawai dan pengunjung

- Jalur warna hitam diperuntukan untuk para WBP.

c) Titik kumpul di bagi menjadi dua dengan tujuan untuk tetap menjaga keamanan dan ketertiban di dalam lapas dengan ketentuan sebagai berikut :

- Titik kumpul pertama berada di lapangan apel para pegawai

- Titik kumpul kedua berada di lapangan olahraga bagi para WBP.

d) Apabila terjadi bencana lanjutan yang menyebabkan kerusakan tembok lapas dan memaksa narapidana harus dievakuasi keluar lapas, maka para narapidana menggunakan jalur berwarna merah dan diamankan di titik kumpul 1 selagi menunggu bantuan dari pihak lain.

e) Dalam pelaksanaannya terdapat ketentuan sebagai berikut :

- Dalam pelaksanaannya untuk letak denah tersebut dilarang di pasang di dalam areal blok/areal steril karena berpotensi dapat mengganggu kemanan dan ketertiban karena para narapidana nanti dapat menggambarkan terkait dengan kondisi dan tata letak Lapas sehingga dapat merencanakan untuk melakukan upaya melarikan diri.

- Untuk pemasangan denah itu sendiri dapat diletakan atau dipasang di titik-titik yang ramai dengan lalu lalang para pegawai dan pengunjung. Yaitu berada di ruangan $\mathrm{P} 2 \mathrm{U}$, ruang kunjungan di mana para pengunjung dan para narapidana dapat melihat mengenai denah tersebut. Kemudian dipasang juga di masingmasing ruangan pegawai dengan tujuan agar pegawai dapat memberikan sosialisasi kepada narapidana dan ketika terjadi gempa para narapidana tidak panik dan sudah paham kemana mereka harus menuju ke titik kumpul/titik aman.

2. Arah jalur evakuasi

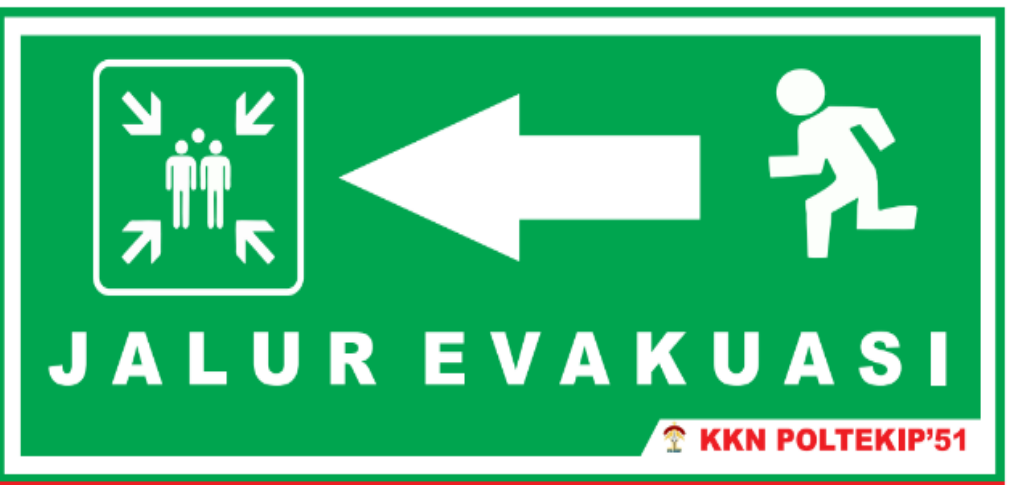




\section{Gambar 2. Arah Jalur Evakuasi}

Jalur evakuasi merupakan suatu fasilitas yang harus ada pada titik-titik rawan bencana dan berusaha mengarahkan kepada zona yang aman(Alhadi, 2014).Jalur evakuasi di pasang pada titik titik rawan di lapas yang berpotensi menyebabkan kecelakaan dan terjebak di dalam bangunan lapas.

3. Titik kumpul

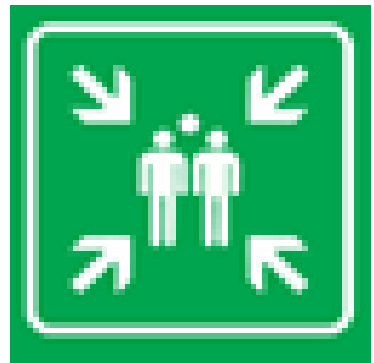

Gambar 3. Titik Kumpul

Titik kumpul atau tempat evakuasi merupakan tempat sementara untuk menampung para korban bencana(Samto Atmodjo, Sangkawati, \& Bayu Setiaji, 2015). Di dalam lapas, pemasangan titik kumpul berada di zona aman dari bencana.

\section{B. Kondisi Real Dikaitkan Dengan Teori Penyebab Kecelakaan.}

Di lapas purwokerto terbagi menjadi 3 bangunan utama yaitu gedung 1 ,Gedung 2 dan Steril area (blok narapidana). Berikut hasil observasi yang dilakukan oleh peneliti untuk menggambarkan kondisi real yang terjadi (das sein) di lembaga pemasyarakatan kelas IIA Purwokerto.

Tabel 1.

Hasil Observasi Langsung di Lapas Kelas IIA Purwokerto Berdasarkan Kondisi Bangunan Dan Akses Yang Diberikan Di Tiap Tiap Bangunan

\begin{tabular}{lcc}
\hline No & Lokasi & Hasil Observasi \\
\hline 1. & Gedung I & Terdiri dari 3 lantai, terdapat lapangan apel untuk pegawai dan \\
& & $\begin{array}{l}\text { parkiran untuk pegawai dan pengunjung. } \\
\end{array}$ \\
& - $\quad$ Temuan : Tidak terdapat rambu rambu K3 yaitu jalur evakuasi di \\
& tiap tiap lantai ,ruangan maupun pintu keluar. Dan juga tidak ada \\
& titik kumpul di areal gedung I. \\
& - & Akses : Hanya dapat diakses oleh pegawai dan pengunjung.
\end{tabular}




\begin{tabular}{|c|c|c|}
\hline 2. & Gedung 2 & $\begin{array}{l}\text { Terdiri dari } 3 \text { ruangan yaitu P2U, KPLP dan ADM KAMTIB dan } \\
\text { satu ruangan kunjungan di samping P2U. } \\
\text { - Temuan : } \\
\text { a) Tidak terdapat rambu rambu K3 yaitu jalur evakuasi di tiap } \\
\text { tiap ruangan ,baik P2U, KPLP, ADM KAMTIB bahkan di } \\
\text { ruang kunjungan. Tidak ada tempat lapang untuk titik } \\
\text { kumpul. } \\
\text { b) Terdapat } 2 \text { pintu utama di P2U . pertama pintu portir untuk } \\
\text { pegawai dan pengunjung. kedua yaitu khusus untuk } \\
\text { kendaraan. } \\
\text { - Akses : Hanya dapat diakses oleh pegawai , pengunjung dan } \\
\text { narapidana yang mendapatkan kunjungan dari keluarganya }\end{array}$ \\
\hline 3. & Steril Area & $\begin{array}{l}\text { - Temuan: } \\
\text { a) Terdiri dari dua areal yang dibatasi oleh pintu 4. Areal } \\
\text { pertama meliputi poliklinik dan dapur serta ruang staff } \\
\text { bimker. Areal kedua meliputi tempat ibadah, ruang } \\
\text { bimbingan kemandirian narapidana,lapangan olahraga dan } 3 \\
\text { blok bangunan. } \\
\text { b) Tidak terdapat rambu rambu K3 yaitu jalur evakuasi di tiap } \\
\text { tiap bangunan, dan tidak ada titik kumpul di lapangan } \\
\text { olahraga. } \\
\text { - Akses : Area steril hanya dapat diakses oleh pegawai dan } \\
\text { narapidana. }\end{array}$ \\
\hline
\end{tabular}

Berdasarkan hasil observasi yang dilakukan oleh peneliti di Lembaga Pemasyarakatan Kelas IIA Purwokerto, ditemukan belum ada rambu rambu mengenai K3, jadi apabila terjadi suatu bencana belum bisa untuk memenuhi HAM narapidana.Mengenai akses dapat menjadi pedoman untuk kondisi yang seharusnya (das sollen) dalam penyusunan tata cara evakuasi narapidana. Dapat dikaitkan antara kondisi real dengan teori domino menurut H.W Heinrich pada tahun 1920-an sebagai berikut :

1. Lapas Kelas IIA Purwokerto belum memiliki program terkait pelaksanaan K3 di dalam lapas. Apabila dikatikan dengan teori domino maka faktor tersebut ideal dengan teori Lock of Control Management (kurang kontrol dari manajemen).Hal ini dikarenakan memenuhi indikator dari teori tersebut yaitu ;

a. Ada atau tidak suatu program. Di lapas purwokerto tidak ditemukan suatu program mengenai pelaksanaan K3 ketika terjadi bencana.

b. Ada atau tidak suatu prosedur. Di lapas purwokerto tidak ada suatu prosedur atau SOP apa yang harus dilakukan ketika terjadi suatu bencana.

2. Belum adanya jalur evakuasi untuk memberikan arah ketika memindahkan narapidana atau tahanan menuju tempat yang aman dan tetap mengutamakan kemanan dan 
ketertiban di dalam lapas/rutan. Disamping itu belum adanya titik kumpul sebagai tanda daerah yang aman dari gempa. Dikaitkan dengan teori domino maka faktor tersebut ideal dengan teori Basic Cause (Sebab Dasar). Hal ini dikarenakan sebagai berikut :

a. Personnel Factor (faktor manusia). Baik narapidana, pegawai maupun masyarakat belum sadar akan pentingnya pelaksanaan rambu-rambu $\mathrm{K} 3$ di dalam lapas.

b. Job Factor (faktor jenis pekerjaan). Bahwa pekerjaan di dalam lapas sangat beresiko. Perlu diketahui bahwa antara pegawai, narapidana dan masyarakat memiliki akses memasuki suatu bangunan atau ruangan yang berbeda beda. Sehingga perlu rambu rambu K3 untuk mengarahkan ketika terjadi bencana.

c. Desain dan pemeliharaan yang kurang memadai. Desain lapas yang sedemikian rupa, terdiri dari beberapa pintu dan area steril mengharuskan adanya rambu rambu K3 untuk memberikan arah untuk menuju zona yang aman. Pemeliharaan mengenai bangunan di lapas yang tidak memperhatikan aspek aspek K3 juga mempengaruhi dalam proses evakuasi narapidana.

3. Belum adanya suatu regulasi yang membahas secara khusus mengenai tata cara evakuasi narapidana ketika terjadi bencana, baik bencana alam maupun bencana lainya. Regulasi merupakan suatu tujuan untuk mencapai kesejahteraan dan keselamatan masyarakat umum. Dikaitkan dengan teori domino maka faktor tersebut ideal dengan teori Immediate Cause (penyebab langsung/ Gejala). Hal ini dikarenakan sebagai berikut :

a. Immediate Cause (penyebab langsung/ Gejala). Ketika terjadi bencana para pegawai hanya menggunakan kebijakan, tidak ada regulasi yang mengatur secara jelas mengenai evakuasi narapidana.Kejadian evakuasi narapidana di Rutan Kabanjahe melalui tembok lapas menjadi bukti bahwa tidak adanya regulasi yang mengatur mengenai pelaksanaan K3 sehingga evakuasi seperti itu sangatlah beresiko bagi keselamatan narapidana.

b. Sub Standard Condition (kondisi yang tidak aman). Melakukan evakuasi tanpa adanya suatu regulasi dapat memperkeruh keadaan. Hal tersebut dapat menimbulkan kondisi yang tidak aman baik bagi pegawai, narapidana maupun pengunjung yang berada di lapas.

Berdasarkan kondisi real dikaitkan dengan teori domino menurut H.W Heinrich maka hal tersebut sesuai dengan teori penyebab kecelakaan menurut H.W Heinrich yaitu Three Main Factory Theory (Teori Tiga Faktor Utama): Penyebab kecelakaan adalah peralatan, lingkungan dan manusia pekerja itu sendiri. Teori tersebut relevan karena peralatan disini adalah rambu rambu K3 yang belum ada di lapas/rutan. Lingkungan yaitu kondisi yang seharusnya dapat diciptkan karena adanya pelaksanaan mengenai rambu rambu K3. Faktor lingkungan yang tidak aman sangat berpengaruh terhadap terjadinya suatu kecelakaan atau 
bencana(Saloni Waruwu, 2013). Maka dari itu perlunya lapas memberikan lingkungan yang aman kepada para narapidana dengan memberikan suatu program K3. Kemudian manusia itu sendiri yaitu pegawai, narapidana dan masyarakat harus menyadari akan pentingnya pelaksanaan rambu rambu K3 dalam rangka memenuhi HAM narapidana untuk mendapatkan hak hidup dan hak atas perlindungan pribadi

\section{Analisis Pemenuhan HAM Narapidana.}

Tabel 2.

Cakupan Kewajiban Negara Terhadap Hak Asasi Manusia

\begin{tabular}{lll}
\hline \multicolumn{1}{c}{ Penghormatan } & \multicolumn{1}{c}{ Perlindungan } & \multicolumn{1}{c}{ Pemenuhan } \\
\hline $\begin{array}{l}\text { State must refrain from } \\
\text { interfering with the }\end{array}$ & $\begin{array}{l}\text { State must prevent private } \\
\text { actors or third parties from } \\
\text { enjoyment of human rights } \\
\text { violating human rights }\end{array}$ & $\begin{array}{l}\text { State must take positive } \\
\text { measures, including }\end{array}$ \\
& & $\begin{array}{l}\text { adopting appropricate } \\
\text { legislation, policies and } \\
\text { programmes, to ensure the } \\
\text { realization of human rights }\end{array}$ \\
\hline
\end{tabular}

Pemenuhan berdasarkan tabel di atas (Agus Anwar. dkk, 2015) yaitu, negara harus mengambil langkah positif, baik mengadopsi undang-undang, kebijakan maupun program. Dalam rangka pemenuhan HAM narapidana di sini lapas/rutan dapat melakukan upaya mengadopsi program. Program di sini adalah mengenai tata cara pelaksanaan rambu rambu K3. Sehubungan dengan hal tersebut pemenuhan HAM yang dimaksud adalah mengenai pasal 28 A yaitu hak untuk hidup dan pasal $28 \mathrm{G}$ yaitu mengenai perlindungan diri pribadi serta berhak mendapatkan rasa aman dari ancaman.

Berikut analisis mengenai hubungan antara kondisi real (das sein) dan kondisi yang seharusnya (das sollen) dengan pemenuhan HAM :

a. Analisis kondisi real terkait belum adanya pelaksanaan rambu rambu K3 di lapas terhadap pemenuhan HAM narapidana.

Tabel 3.

Analisis Kondisi Realita (Das Sein) Pelaksanaan K3 di Lapas

\begin{tabular}{|c|c|c|}
\hline Hak Asasi Manusia & $\begin{array}{c}\text { Tidak Ada Rambu Rambu } \\
\text { K3 }\end{array}$ & Analisis Pemenuhan HAM \\
\hline $\begin{array}{l}\text { Pasal } 28 \text { A yaitu hak untuk } \\
\text { hidup }\end{array}$ & $\begin{array}{l}\text { Belum ada mengenai } \\
\text { program pelaksanaan rambu } \\
\text { rambu K3 ketika terjadi } \\
\text { bencana berupa denah }\end{array}$ & $\begin{array}{l}\text { Narapidana tidak } \\
\text { mendapatkan jaminan untuk } \\
\text { hidup ketika terjadi bencana. } \\
\text { Tidak adanya suatu denah }\end{array}$ \\
\hline
\end{tabular}




\begin{tabular}{|c|c|}
\hline & $\begin{array}{l}\text { menyebabkan para } \\
\text { narapidana tidak mengetahui } \\
\text { bagaimana upaya yang harus } \\
\text { dilakukan untuk } \\
\text { menyelamatkan diri dan } \\
\text { mempertahankan hidupnya. } \\
\text { Narapidana tidak mengetahui } \\
\text { dimana zona aman di dalam } \\
\text { lapas untuk mengamankan } \\
\text { diri dari bencana. }\end{array}$ \\
\hline 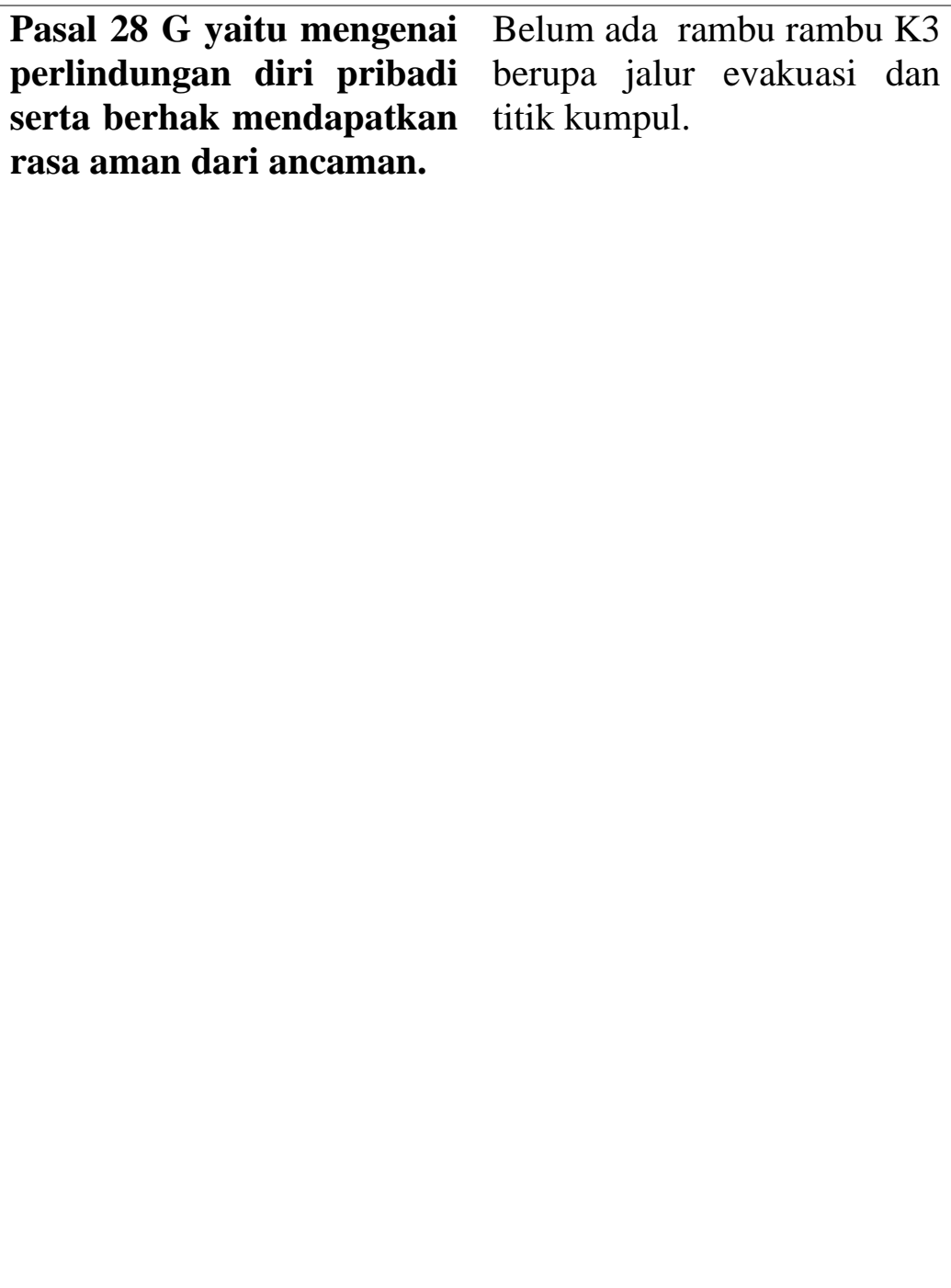 & $\begin{array}{lr}\text { - } \text { Tidak adanya suatu jalur } \\
\text { evakuasi menyebabkan } \\
\text { narapidana tidak bisa } \\
\text { untuk melindungi dirinya } \\
\text { sendiri. Ketika terjadi } \\
\text { bencana narapidana yang } \\
\text { panik tidak mengetahui } \\
\text { kemana ia harus } \\
\text { menyelamatkan r diri. } \\
\text { Desain bangunan lapas } \\
\text { yang sedemikian rupa } \\
\text { sangat riskan } \\
\text { menyebabkan narapidana } \\
\text { terjebak di dalam } \\
\text { bangunan. } \\
\text { - Tidak adanya suatu titik } \\
\text { kumpul rapat } \\
\text { menyebabkan narapidana } \\
\text { tidak dapat menentukan } \\
\text { dimana zona aman ketika } \\
\text { ada bencana di dalam } \\
\text { lapas. Akibatnya tidak } \\
\text { jarang narapidana justru } \\
\text { menggunakan segala cara } \\
\text { untuk merusak sarana dan } \\
\text { prasarana lapas untuk } \\
\text { mencari zona yang aman } \\
\text { seperti kasus di palu dan di } \\
\text { rutan kabanjahe. }\end{array}$ \\
\hline
\end{tabular}

b. Analisis kondisi yang seharusnya mengenai pelaksanan K3 di lapas terhadap pemenuhan HAM narapidana :

Tabel 4.

Analisis Kondisi Seharusnya (Das Sollen) Pelaksanaan K3 di Lapas 


\begin{tabular}{|c|c|c|}
\hline $\begin{array}{l}\text { Pasal } 28 \text { A yaitu hak } \\
\text { untuk hidup }\end{array}$ & $\begin{array}{l}\text { Adanya suatu program } \\
\text { pelaksanaan rambu rambu K3 } \\
\text { ketika terjadi bencana berupa } \\
\text { denah beserta tata cara } \\
\text { pelaksanaannya. }\end{array}$ & $\begin{array}{l}\text { Dengan memberikan denah } \\
\text { beserta tata cara pelaksanaan } \\
\text { evakuasi kepada narapidana, } \\
\text { disini negara yaitu lapas/rutan } \\
\text { telah memberikan jaminan hak } \\
\text { hidup bagi para narapidana } \\
\text { nya.Sehingga apabila terjadi } \\
\text { bencana, baik bencana alam } \\
\text { maupun bencana lainya, } \\
\text { narapidana diperkenankan } \\
\text { menyelamatkan diri untuk } \\
\text { mempertahankan hidupnya } \\
\text { sesuai dengan denah yang telah } \\
\text { di tentukan }\end{array}$ \\
\hline $\begin{array}{lr}\text { Pasal 28 G yaitu } \\
\text { mengenai } & \\
\text { perlindungan } & \text { diri } \\
\text { pribadi serta } & \text { berhak } \\
\text { mendapatkan } & \text { rasa } \\
\text { aman dari ancaman. }\end{array}$ & $\begin{array}{l}\text { Implementasi rambu rambu K3 } \\
\text { berupa jalur evakuasi dan titik } \\
\text { kumpul. }\end{array}$ & $\begin{array}{l}\text { - Dengan mengimplementasikan } \\
\text { jalur evakuasi sehingga } \\
\text { narapidana dapat melindungi } \\
\text { dirinya masing masing untuk } \\
\text { mengikuti jalur evakuasi yang } \\
\text { telah ditentukan. } \\
\text { - Dengan mengimplementasikan } \\
\text { titik kumpul pihak lapas telah } \\
\text { memberikan zona yang aman } \\
\text { dari bencana, pihak lapas telah } \\
\text { memberikan tempat rasa aman } \\
\text { terhadap narapidana dari } \\
\text { adanya suatu bencana, baik } \\
\text { bencana alam maupun bencana } \\
\text { lainya. }\end{array}$ \\
\hline
\end{tabular}

Berdasarkan analisis diatas, bahwa kondisi real didalam lapas tidak bisa memenuhi HAM narapidana yaitu mengenai pasal 28 A yaitu hak untuk hidup dan pasal 28 G yaitu mengenai perlindungan diri pribadi serta berhak mendapatkan rasa aman dari ancaman. Namun kondisi seharusnya mengenai pelaksanaan rambu rambu K3 di dalam lapas dapat memenuhi mengenai HAM tersebut. Maka dari itu diperlukan suatu implementasi mengenai rambu rambu K3 didalam Lapas untuk memenuhi HAM narapidana.

\section{KESIMPULAN}

Implementasi rambu-rambu K3 merupakan kewajiban negara khususnya pemerintah di bidang HAM agar dapat memenuhi HAM narapidana yaitu mengenai hak untuk hidup dan hak atas perlindungan pribadi. Dengan memberikan lingkungan yang aman maka negara telah memenuhi HAM narapidana atas hak untuk hidup dan perlindungan pribadi narapidana. Selaras dengan teori yang di kemukakan menurut H.W Heinrich pada tahun 1920-an yaitu Three Main 
Factory Theory (Teori Tiga Faktor Utama): Penyebab terjadinya kecelakaan adalah peralatan, lingkungan dan manusia pekerja itu sendiri. Maka dari itu di sini rambu-rambu K3 bertindak sebagai peralatan. Rambu rambu K3 berupa prosedur, denah, jalur evakuasi dan titik kumpul. Denah dan prosedur pelaksanaan evakuasi bertindak sebagai upaya menciptakan lingkungan yang aman. Dengan adanya denah, negara telah berupaya membentuk lingkungan yang sedemikian rupa untuk menghadapi gempa bumi atau bencana lainya. Narapidana, pegawai, dan masyarakat bertindak sebagai manusia pekerja itu sendiri. Kemudian pemberian sosialisasi kepada narapidana, pegawai, dan masyarakat luar bertujuan agar pelaksanaan evakuasi dapat berjalan sesuai prosedur. Karena kesadaran manusia itu sendiri mengenai K3 merupakan faktor utama dalam meminimalisir adanya korban jiwa akibat kecelakaan. Dengan memenuhi Three Main Factory Theory (Teori Tiga Faktor Utama) menurut H.W Heinrich diharapkan dapat mengantisipasi terjadinya suatu kecelakaan akibat bencana, baik bencana alam maupun bencana lainya seperti kerusuhan dan kebakaran di dalam lapas. Pentingnya PDCA yaitu Planning Do Check Action dalam setiap tahapan proses evakuasi merupakan suatu wujud implementasi tanggung jawab negara kepada narapidana.Sehingga implementasi rambu rambu K3 dapat memenuhi HAM narapidana atas hak untuk hidup dan perlindungan pribadi.

\section{REFERENSI}

Alhadi, Zikri. (2014). “Kesiapan Jalur Dan Lokasi Evakuasi Publik Menghadapi Resiko Bencana Gempa Dan Tsunami Di Kota Padang (Studi Manajemen Bencana)." Humanus 13 (1): 35. https://doi.org/10.24036/jh.v13i1.4095.

Amanda, Putri Kusuma. (n.d). Jaminan HAM Serta Kewajiban dan Tanggung Jawab Negara Terhadap Perlindungan, Penegakan dan Pemenuhan HAM di Indonesia. Jakarta: Direktorat Pengembangan HAM.

Anwar, Agus, dkk. (2015). Indikator Hak Atas Rasa Aman. Jakarta: Badan Penelitian dan Pengembangan Hak Asasi Manusia Kementerian Hukum dan HAM

Sucita, I. K., \& Broto, A. B. (2011). Indentifikasi Dan Penanganan Risiko K3 Pada Proyek Konstruksi Gedung. Poli Teknologu, 10(1).

Indonesia, CNN. (2018). Kronologi 1.425 Tahanan Kabur saat Diguncang Gempa Palu. Retrieved from CNN Indonesia website: https://www.cnnindonesia.com/nasional/20181001164047-20-334710/kronologi-1425tahanan-kabur-saat-diguncang-gempa-palu

Indonesia, CNN. (2020). Kerusuhan di Rutan Kabanjahe, 20 Narapidana Jadi Tersangka. Retrieved from CNN Indonesia website: https://www.cnnindonesia.com/nasional/20200213125613-12-474249/kerusuhan-di- 
rutan-kabanjahe-20-narapidana-jadi-tersangka

Raco, J.R. (2010) . Metode Penelitian Kualitatif. Jakarta: Grasindo.

Irzal. (2016). Dasar Dasar Kesehatan Dan Keselamatan Kerja. Jakarta: Kencana.

Estetika, Rio. (2016). “Analisis Kelayakan Buku Ajar Al Islam Dan Kemuhammadiyahan Berwawasan HAM.” Tajdida.

Hamidah, Tutik. (2008). "Hak-Hak Asasi Manusia Dalam Hukum Islam." El-HARAKAH (TERAKREDITASI) 2 (1): 3. https://doi.org/10.18860/el.v2i1.4721.

Ismainar, Hetty. (2015). Keselamatan Pasien Di Rumah Sakit. Yogyakarta: Deepublish.

Jasman, Sihaloho Rufinus. (1997). "Pembelaan Hak Azasi Manusia Merupakan Jalan Tanpa Ujung.” Jurnal I-Lib UGM, 30-37.

Kartono Tjandra. (2017). Empat Bencana Geologi Yang Paling Mematikan. Yogyakarta: Gadjah Mada University Press.

Matompo, Osgar S. (2014). "Pembatasan Terhadap Hak Asasi Manusia Dalam Prespektif Keadaan Darurat.” Media Hukum 21 (1): 57-72.

Nurkholis and Gusti Adriansyah. (2017). "Pengendalian Bahaya Kerja Dengan Metode Job Safety Analysis Pada Penerimaan Afval Lokal Bagian Warehouse Di Pt. St." Teknika: Engineering and Sains Journal 1 (1): 11-16. https://doi.org/10.5281/zenodo.1115956.

Pangaribuan, Luhut. (2017). "Hak Asasi Manusia." Jurnal Hukum \& Pembangunan. https://doi.org/10.21143/jhp.vol19.no6.1180.

Dwi Djatmiko, Riswan. (2016). Kesehatan Dan Keselamatan Kerja. Yogyakarta: Deepublish.

Saloni Waruwu, Ferida Yuamita. (2013). “Analisis Faktor Kesehatan Dan Keselamatan Kerja (K3) Yang Signifikan Mempengaruhi Kecelakaan Kerja Pada Proyek Pembangunan Apartement Student Castle.Spektrum Industri." Issn 14(1): 1-108.

Samto Atmodjo, Pranoto, Sri Sangkawati, and Arief Bayu Setiaji. (2015). “Analisis Efektivitas Jalur Evakuasi Bencana Banjir." Media Komunikasi Teknik Sipil 21 (1): 23. https://doi.org/10.14710/mkts.v21i1.11228.

Susihono, Wahyu, and Feni Akbar Rini. (2013). "Penerapan Sistem Manajemen Keselamatan Dan Kesehatan Kerja (K3) Dan Identifikasi Potensi Bahaya Kerja (Studi Kasus Di PT. LTX Kota Cilegon- Banten)." Spektrum Industri $11 \quad$ (2): 209. https://doi.org/10.12928/si.v11i2.1663.

Triwahyuningsih, Susani. (2018). "Perlindungan Dan Penegakan Hak Asasi Manusia (Ham) Di Indonesia." Legal Standing: Jurnal Ilmu Hukum 2 (2): 113. https://doi.org/10.24269/1s.v2i2.1242.

Widari, Lis Ayu. (2018). "Analisis Pengaruh Keselamatan Dan Kesehatan Kerja ( K3 ) Terhadap Kinerja Pekerja Konstruksi ( Studi Kasus Proyek The Manhattan Mall and Condominium )" 8 (1): 329-38.

Wiwaha, Adam Abraham, Estuning Tyas Wulan Mei, and Rini Rachmawati. (2016). "Perencanaan Partisipatif Jalur Evakuasi Dan Titik Kumpul Desa Ngargomulyo Dalam Upaya Pengurangan Resiko Bencana Gunungapi Merapi.” Journal of Regional and City Planning 27 (1): 34-48. https://doi.org/10.5614/jrcp.2016.27.1.4. 